Dokuz Eylül Üniversitesi-Mühendislik Fakültesi

Fen ve Mühendislik Dergisi

Cilt 19, Sayı 56, Mayıs 2017
Dokuz Eylul University-Faculty of Engineering Journal of Science and Engineering Volume 19, Issue 56, May 2017

DOI: $10.21205 /$ deufmd. 2017195646

\title{
Fotovoltaik Güneş Pillerinde Kullanılan ZnO ve CuO Filmlerinin SILAR Yöntemi ile Üretilmesi ve Karakterizasyonu
}

\section{Olcay GENÇYILMAZ ${ }^{* 1}$, Turan TAŞKÖPRÜ ${ }^{1}$}

${ }^{1}$ Çankırı Karatekin Üniversitesi, Çerkeş Meslek Yüksek Okulu, Malzeme ve Malzeme İşleme Teknolojileri Bölümü, 18100, Çankırı

${ }^{1}$ Çankırı Karatekin Üniversitesi, Fen Fakültesi, Fizik Bölümü, 18100, Çankırı

(Alınış / Received: 07.07.2016, Kabul / Accepted: 10.11.2016, Online Yayınlanma / Published Online: 02.05.2017)

Anahtar Kelimeler Fotovoltaik güneş pilleri, $\mathrm{ZnO}$ ve $\mathrm{CuO}$ filmleri, SILAR, $\mathrm{XRD}$, SE, AFM
Bu çalıșmada $\mathrm{ZnO}$ ve $\mathrm{CuO}$ filmleri pratik ve ekonomik bir teknik olan SILAR (Successive Ionic Layer Adsorption and Reaction) yöntemi ile üretilmiştir. Filmlerin yapısal, optik, elipsometrik, yüzeysel ve elektrik özellikleri sırası ile XRD, UV spektroskopisi, Spektroskopik Elipsometre (SE), Atomik Kuvvet Mikroskobu (AFM) ve dört-uç tekniği kullanılarak incelenmiștir. Filmlerin yasak enerji aralıkları, optik metot kullanılarak 3,22 eV-1,72 eV olarak hesaplanmıștır. Spektroskopik elipsometre (SE) tekniği ile filmlerinin kalınlıkları ve bazı optik sabitleri (sönüm katsayısı ve kırılma indisi) belirlenmiştir. Ayrıca, filmlerin üç boyutlu yüzey görüntüleri incelenmiş ve ortalama yüzey pürüzlülük değerleri $38 \mathrm{~nm}$ and $60 \mathrm{~nm}$ olarak tespit edilmiștir. Filmlerin elektriksel özdirenç değerleri ve iletim tipi sırasıyla dört-uç metodu ve sıcak uç tekniği kullanılarak belirlenmiştir.

The Production of $\mathrm{ZnO}$ and CuO Films by SILAR Method and Characterization for Use in Photovoltaic Solar Cells

\begin{tabular}{ll}
\hline Keywords & Abstract: In this study; ZnO and CuO films were produced by \\
Photovoltaic & SILAR (Successive Ionic Layer Adsorption and Reaction) \\
solar cells, & technique which is a practically and economic. The films of \\
ZnO and CuO & structural, optical, ellipsometric, surface and electrical properties \\
films, & were determined by XRD diffactometer, UV spectrophotometer, \\
SILAR, & Spectroscopic Ellipsomery (SE), Atomic Force Microscope (AFM), \\
XRD, & Four-Probe, respectively. The band gaps of films were calculated \\
SE, & as 3.22 eV-1.72 eV using optic method. The thickness and some \\
AFM & optic constants (extinction coefficient and refractive index) of \\
& films were investigated by SE. Also, the three dimensional surface \\
& images of films were obtained and the average surface roughness \\
& values were determined as 38 and 60 nm. The electrical resistivity \\
& values and conduction mechanism were investigated by using \\
& four-probe and hot-probe technique, respectively.
\end{tabular}

*Olcay Gençyılmaz: ogencyilmaz@karatekin.edu.tr 


\section{Giris}

Son yıllarda, yapılan araștırma ve geliştirme çalışmaları fotovoltaik güneş pillerinde kullanılan malzemelerin üretilmesi ve geliștirilmesine olanak sağlamıştır. $\mathrm{Bu}$ malzemeler arasında saydam iletken oksitler, elektrik ve optik özellikleri nedeni ile güneş pili üretiminde yaygın olarak kullanılan yariletken filmler arasındadır. Saydam iletken oksit grubuna ait çinko oksit ( $\mathrm{ZnO})$ ve bakır oksit $(\mathrm{CuO})$ yariletken filmleri üzerinde en çok çalışılan malzemeler arasındadır. $\mathrm{ZnO}$ ve $\mathrm{CuO}$ filmleri, opto-elektronik aygitların üretiminde sıklıkla kullanılan, üzerinde çok sayıda araştırma yapılmış ve halen çalışılmakta olan malzemelerdir. $\mathrm{Bu}$ filmlerin üretimi ve geliştirilmesinde farklı yöntemler kullanılmış ve daha çok ZnO filmleri üzerine yoğunlaşılmıştır [1]. Hem mikro-elektronik hem de optoelektronik cihazlarda kullanilabilen saydam iletken oksit malzemelerin başında $\mathrm{ZnO}$ filmleri gelmektedir [2]. $\mathrm{CuO}$ filmlerinin ise farklı uygulama alanlarında uygulanabilirliği araştırılmıştır [3-11].

$\mathrm{ZnO}$; periyodik cetvelin II B ve VI A grubu elementlerinden oluşan ve yariletken özellik gösteren bir bileşiktir. ZnO filmleri, oda sıcaklığında geniş bant aralığına ( 3.1-3.4 eV) ve yüksek eksiton bağlanma enerjisine (60meV) sahiptir. Görünür bölgede yüksek geçirgenlik ve elektriksel iletkenlik değerlerine sahiptir. Ayrıca, direkt bant aralıklı, n-tipi/p-tipi olarak üretilebilen, fiziksel özellikleri ısıl işlem veya katkılama ile kolaylıkla değişebilen, ekonomik, çevre dostu ve uzun ömürlü malzemelerdir $[12,13]$.

Bakır (Cu) periyodik cetvelin I B grubunda bulunan kırmızı renkli bir kimyasaldır. Bakır, açık havada ısıtıldığında, kolayca siyah renkli $\mathrm{CuO}$ 'ya dönüşür. Bakır oksit (CuO) filmleri ise IB ve VIA gruplarından oluşan yariiletken bir bileşiktir. CuO filmlerinin elektrik iletkenliği çok yüksek olduğundan en önemli kullanım alanı elektrik-elektronik sanayidir [14]. CuO (tenorite) ve $\mathrm{Cu}_{2} \mathrm{O}$ (cuprite) olmak üzere iki genel bileşik halinde oluşur ve saydam iletken oksit grubundan p-tipi iletkenlik özellik gösteren, üzerinde en çok çalışılan malzemelerden biridir $[9,15]$.

ZnO ve CuO filmleri; darbeli lazer çöktürme [13], radyo frekans magnetron saçtırma [14], kimyasal buhar çöktürme [15], sol-gel [16], reaktif termal buharlaştırma [17], SILAR [18] ve kimyasal püskürtme [19,20] gibi farklı fiziksel ve kimyasal ince film üretme teknikleri kullanılarak üretilebilirler. $\mathrm{ZnO}$ ve $\mathrm{CuO}$ yarıiletken filmlerinin kullanım potansiyelini ve üretim verimini arttırmak için ekonomik olarak üretilmesi gerekmektedir. Farklı üretim teknikleri kullanılarak pek çok araştırma yapılmasına rağmen bu filmlerinin SILAR tekniği ile üretimi ve geliștirmesi üzerine yapılan çalışmalar çok kısıtlıdır [21].

SILAR tekniği ile üretilen $\mathrm{ZnO}$ ve $\mathrm{CuO}$ filmlerinin özellikle elipsometrik karakterizasyonu ve yüzey özellikleri hakkındaki araştırma çok azdır [22, 23]. $\mathrm{Bu}$ nedenlerden dolayı; bu çalışmada, SILAR tekniği kullanılarak hem n-tipi $\mathrm{ZnO}$ hem de p-tipi $\mathrm{CuO}$ yariletken filmlerinin üretimi gerçekleștirilmiştir. Filmlerin yapısal, optik, elipsometrik, elektrik ve yüzey karakterizasyonları yaplarak fiziksel özellikleri incelenmiștir.

\section{Materyal ve Metot}

\subsection{ZnO ve CuO Filmlerin Üretimi}

SILAR tekniği temel olarak, çözeltideki iyonların adsorpsiyonu ve reaksiyonu; sonrasında çözeltideki homojen çökelmeden kaçınmak için deiyonize su ile gerektiği kadar durulama işlemi 
aşamalarından oluşur. $\mathrm{Bu}$ teknikte özgün olan, taban malzeme üzerinde bir maddenin diğer madde üzerinde biriktirilmesidir (adsorpsiyon).

Adsorpsiyon olayı, farklı iki fazın temasının sağlanmasıyla gerçekleştirilir. Filmlerin depolanması taban malzemenin yüzeyi ile çözelti içerisinde bulunan iyonlar arasındaki bağlayıcı kuvvetler olan Van-der Waals kuvvetleri veya kimyasal çekim kuvvetlerinden kaynaklanan bir süreçtir. Adsorpsiyon sürecinde, büyüme hızı, sıcaklık, basınç, taban özellikleri, yüzey alanı ve konsantrasyon gibi etkenler verimi etkileyen faktörlerdir [25-27].

SILAR tekniğinde, reaksiyonun oda sıcaklığında veya oda sicaklığı civarındaki sıcaklıklarda gerçekleştirilmesi, yalıtkan, yariletken, metal ve polyester gibi sıcaklığa duyarlı taban malzemelerin kullanımına izin vermektedir. Böylece taban malzemenin oksidasyonu ve korozyonu önlenebilir. $\mathrm{Bu}$ teknik ile üretilen filmlerin kalitesinin artırılması; konsantrasyon, çözelti pH'sı, adsorpsiyonu, reaksiyon ve durulama zamanı parametrelerinin optimizasyonu ile sağlanabilir. Ayrıca bu teknikte film biriktirme işlemine ilişkin büyütme kinetiği, daldırılmış yüzeyler üzerindeki çekirdeklenme bölgelerinde meydana gelen iyon bazlı biriktirme esaslıdır. Koloidal iyonların adsorpsiyonu ile çekirdeklenme; bu iyonların yüzey koagülasyonu sonucunda da büyüme gerçekleşir ve böylece ince ve yapışık bir film elde edilir [23]. Bu nedenle, SILAR tekniği ile film oluşumu, çok düşük çözünürlüğe sahip bir iyon çiftinin oluşturduğu ürünün katı bir yüzeye elektrostatik mekanizmalarla sıkıca tutunması esasına dayanır [25]. Tek bir SILAR biriktirme döngüsü, tabanın dönüşümlü olarak katyonik ve anyonik öncül çözeltilere daldırılması ve ardışık daldırmalar arasinda, istenmeyen maddelerin uzaklaştırılması amacıyla deiyonize su ile durulama işlemleri yapilır.

$\mathrm{Bu}$ çalışmada; $\mathrm{ZnO}$ ve $\mathrm{CuO}$ filmleri, SILAR tekniği kullanılarak mikroskop cam altlıklar (Objekttrager marka) üzerine depolanarak elde edilmiştir. Öncelikle cam altlıklar sırasıyla aseton, etanol ve deiyonize su kullanılarak ultrasonik banyo da ayrı ayrı 15 dakika süreyle yıkanmıştır. Temizlenen camlar firında kurutulmuştur. Daha sonra, ZnO ve $\mathrm{CuO}$ filmlerin elde edilmesi için çinko kaynağı olarak altı sulu çinko nitrat $\left[\mathrm{Zn}\left(\mathrm{NO}_{3}\right)_{2} \cdot 6 \mathrm{H}_{2} \mathrm{O}\right]$ ve bakır kaynağı olarak iki sulu bakır klorür $\left[\mathrm{CuCl}_{2} .2 \mathrm{H}_{2} \mathrm{O}\right]$ kimyasal tuzu kullanılmıştır. Her iki çözelti de molaritesi $0.3 \mathrm{M}$, miktarı ise $200 \mathrm{ml}$ olarak hazırlanmıştır. Çözeltilere $\% 28$ derişimli amonyak $\left(\mathrm{NH}_{3}\right)$ eklenerek, pH değeri 9.5 olan katyonik bileşik çözeltileri ayrı ayrı elde edilmiștir. Oksitleyici olarak $90 \quad{ }^{\circ} \mathrm{C}$ sıcaklıktaki $200 \mathrm{ml}$ saf su kullanılmıștır. Çözeltilerin hazırlanmasının ardından temizlenip kurutulan cam altlıklar kullanılarak film elde etme işlemine geçilmiştir. Filmlerin üretiminde SILAR döngüsü oda sıcaklığında iki aşamalı olarak gerçekleştirilmiştir. Birinci adımda cam altlıklar bakır klorür bileşik çözeltisine daldırılır ve $20 \mathrm{~s}$ bekletilir ve bakır iyonlarının cam yüzeyine tutunması sağlanır. İkinci adımda sıcak suya daldırılır ve $20 \mathrm{~s}$ bekletilir. Böylece $\mathrm{OH}^{-}$iyonlarının daha önce cam yüzeyine tutunan $\mathrm{Cu}^{2+}$ iyonlariyla reaksiyona girerek $\mathrm{Cu}(\mathrm{OH})_{2}$ tabakasının oluşumu sağlanır. Böylece tam bir SILAR döngüsü tamamlanmış olur. Her döngüde bir miktar $\mathrm{Cu}(\mathrm{OH})_{2}$ tabakası oluşur ve bu işlem istenilen kalınlıkta film elde edilene kadar tekrarlanabilir. ZnO ve $\mathrm{CuO}$ için ilgili reaksiyonlar şu şekildedir [42]:

Amonyak ve su reaksiyonu sonucu hidroksit iyonları oluşur. 
O. Gençyılmaz vd. / Fotovoltaik Güneş Pillerinde kullanılan ZnO ve CuO Filmlerinin SILAR Yöntemi ile Üretilmesi ve Karakterizasyonu

$\mathrm{NH}_{3}+\mathrm{H}_{2} \mathrm{O} \rightarrow \mathrm{NH}_{4}^{+}+\mathrm{OH}^{-}$

Çinko ve bakır iyonları hidroksit ile reksiyona girer.

$\mathrm{ZnO}_{3}+2 \mathrm{NH}_{4} \mathrm{OH} \rightarrow \mathrm{Zn}(\mathrm{OH})_{2}+2 \mathrm{NH}_{4} \mathrm{NO}_{3}$ (2)

$\left[\mathrm{Cu}\left(\mathrm{H}_{2} \mathrm{O}\right)_{6}\right]^{2+}+2 \mathrm{OH}^{-} \rightarrow(\mathrm{CuOH})_{2} 2 \mathrm{H}_{2} \mathrm{O}+$ $2 \mathrm{H}_{2} \mathrm{O}$

(3)

İyonik reaksiyonlar elde edilmiş olur.

$\mathrm{Zn}^{2+}+2 \mathrm{OH}^{-} \rightarrow \mathrm{Zn}(\mathrm{OH})_{2}$

$\mathrm{Cu}^{2+}+2 \mathrm{OH}^{-} \rightarrow \mathrm{Cu}(\mathrm{OH})_{2}$

Sonuç olarak $\mathrm{ZnO}$ ve $\mathrm{CuO}$ bileşiği elde edilir.

$$
\begin{aligned}
& \mathrm{Zn}(\mathrm{OH})_{2} \rightarrow \mathrm{ZnO}+\mathrm{H}_{2} \mathrm{O} \\
& \mathrm{Cu}(\mathrm{OH})_{2} \rightarrow \mathrm{CuO}+\mathrm{H}_{2} \mathrm{O}
\end{aligned}
$$

$\mathrm{Bu}$ çalışmada oda sicaklığında gerçekleştirilen SILAR döngüsü 10 olarak seçilmiştir. Elde edilen filmler kurumaya bırakılmış ve daha sonra hava ortamında hidroksil fazdan kurtulmak ve $\mathrm{CuO}$ oluşumunu sağlamak için $400{ }^{\circ} \mathrm{C}$ sicaklıkta 2 saat süreyle tavlanmıştır. Elde edilen filmlerin resimleri Şekil 1'de gösterilmiştir. ZnO toz beyaz (kireç) renginde, $\mathrm{CuO}$ ise kahverengi bir oluşum göstermiştir.

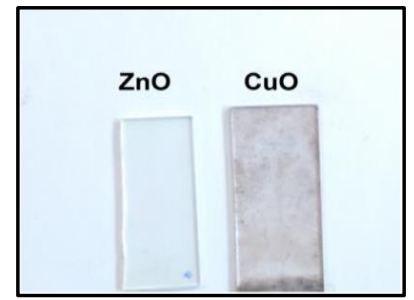

Şekil 1. SILAR tekniği ile elde edilen $\mathrm{ZnO}$ ve CuO filmleri

\subsection{Yapılan Analizler ve Kullanılan Karakterizasyon Teknikleri}

Elde edilen filmlerin yapısal özellikleri X-ışını kırınım desenleri yardımı ile incelenmiştir. X-ışını kırınım desenleri Bruker D8 Advance $\left(C u K_{\alpha}(\lambda=1,54 \AA\right.$ ) $)$ marka X-ışını cihazı kullanılarak, $20^{\circ} \leq$ $2 \theta \leq 70^{\circ}$ (ZnO filmleri için) ve $30^{\circ} \leq 2 \theta \leq$ $80^{\circ}$ (CuO fimleri için) açı aralığında 0,1 derece/saniye tarama hiziyla ile alınmıştır. Filmlerin kristalleşme seviyeleri hakkında bilgi edinilenerek tercihli yönelimleri, tane büyüklükleri, yapılanma katsayıları ve kristalleşme seviyesi incelenmiştir.

Filmlerin kalınlıkları ve optik özelliklerini belirlemek için PHE 102 Spektroskopik Elipsometre ve UV-2550 UV-Vis Spektrofotometre cihazları kullanılmıştır. Tüm filmlerin kalınlıkları $(t), \cos$ (delta)-psi ( $\Psi$ ) parametreleri, kırılma indisleri $(n)$ ve sönüm katsayıları (k) 250-2300 nm ölçüm aralıklı PHE 102 Spektroskopik Elipsometre cihazl; geçirgenlik (T), absorbans $(A)$ ve yansıma $(R)$ spektrumları ise 200-1100 nm ölçüm aralıklı UV-2550 UV-Vis Spektrofotometre cihazı kullanılarak alınmıştır. Ayrıca optik metot ile tüm filmlerin yasak enerji aralıkları $\left(E_{g}\right)$ belirlenmiştir.

Elde edilen filmlerin yüzey topografisi, Park System XE 70 model atomik kuvvet mikroskobu (AKM) ile non-contact modda yaklaşık $300 \mathrm{kHz}$ titreşim frekansında ve $0.75 \mathrm{~Hz}$ tarama hızında, hava ortamında, oda sıcaklığında alınmıştır. Yay ve tip Si'dan yapılmıştır ve yay sabiti $40 \mathrm{~N} / \mathrm{m}$ 'dir. Ayrica rms $\left(R_{q}\right)$, ortalama $\left(R_{a}\right)$ ve pik-vadi $\left(R_{p v}\right)$ pürüzlülük değerleri XEI version 1.7.1 yazılımı kullanılarak belirlenmiştir.

Tüm filmler için görüntüler $5 \times 5 \mu \mathrm{m}^{2}$ alanlı bölgeler taranarak alınmıştır ve 
pürüzlülük değerleri de tüm taranan bölge üzerinden belirlenmiştir.

Ayrıca filmlerin elektriksel özdirençleri de Keithley 2601 A System Source meter Lucas Labs dört uç sistemi ile ölçülmüştür. Filmlerin iletim tipi ise sıcak uç metodu ile tespit edilmiştir.

\section{Bulgular}

\subsection{Yapısal Analiz}

$\mathrm{ZnO}$ ve $\mathrm{CuO}$ filmlerinin XRD desenlerinde gözlenen piklere ait kırınım açıları $(2 \theta)$, düzlemler arası uzaklıkları (d), miller indisleri $(h k l)$, kristal sistemleri, yapılanma katsayıları $\left(T C_{(h k l)}\right)$, dislokasyon yoğunluğu $(\delta)$, makro gerilmeler $(<e>)$ ve tane boyutu (D) değerlerini belirlenmek için aşağıdaki formüllerden yararlanılmıştır ve bu hesaplamalar Tablo 1'de verilmiștir.

XRD verilerinden yararlanarak bir kristalin tercihli yönelimini belirlemek için Haris analizi yapılır. Yapılanma katsayısı ifadesi;

$T C=\frac{I_{(h k l)} / I_{0}(h k l)}{N^{-1} \sum I_{(h k l)} / I_{0}(h k l)}$

ile verilir. Burada, $I_{0} \quad(h k l) ; \quad(h k l)$ düzleminin standart şiddetini, I (hkl); ( $h k l$ ) düzleminin gözlenen şiddetini ve $N$ ise kırınım deseni üzerindeki toplam pik sayısını ifade eder [28].

XRD desenlerinden yararlanarak bir kristalin tane büyüklüğü,

$D=\frac{0.9 \lambda}{\beta \cos \theta}$

șeklinde ifade edilen Scherrer eşitliği ile hesaplanmaktadır. Burada, $D$; tane büyüklüğü, $\lambda$; gönderilen $\mathrm{X}$-ışının dalgaboyu, $\beta$; ilgili kristal yönü için radyan olarak yarı pik genişliği, $\theta$, pikin maksimum şiddet değerine karşılık gelen açıyı gösterir [29].
Makro gerilmeler ise, örgü parametreleri değișeceğinden XRD deseninde oluşan kaymalar sonucu anlașılır [30]. Bu kusurlara bağlı olarak elde edilen XRD desenlerinden malzemenin dislokasyon yoğunluğu $(\delta)$ ve makro gerilme $(<e>)$ değerleri hesaplanabilir.

Dislokasyon yoğunluğu; bir malzemenin belli bir kismında bulunan dislokasyonların sayısının bir ölçüsüdür. Ayrıca kristal yapıların atomsal dizilişlerinde bir çizgi boyunca görülen kusurlar olarak da tanımlanır. Dislokasyon yoğunluğu Williamson ve Smallman tarafindan verilen,

$\delta=\frac{n}{D^{2}}$

ifadesi kullanılarak hesaplanabilir [31]. Minimum $\delta$ değeri için $n=1$ alınır. Küçük $\delta$ değerleri malzemenin kristalleşme seviyesinin iyi olduğunu gösterir [32].

XRD desenlerinde gözlenen piklerin pozisyonlarındaki kaymalar ile varlığını gösteren makro gerilme kusuru ise, sıkıșmış veya genişlemiş örgü düzlemlerine sahip tanelerin bulunduğunu gösterir [32]. Makrogerilme <e>;

$<e>=\frac{d-d_{0}}{d_{0}}$

eşitliği kullanılarak hesaplanabilir. Burada $d$; deformasyon halinde düzlemler arası mesafeyi ve $d_{0}$ ise deformasyon olmadığı durumdaki düzlemler arasındaki mesafeyi göstermektedir [33].

$\mathrm{ZnO}$ ve $\mathrm{CuO}$ filmlerinin XRD kırınım desenleri Şekil 2'de verilmiştir. Şekil 2 (a) incelendiğinde; ZnO'e ait (100), (002), (101), (102), (103) ve (200) olmak üzere altı adet pikin olduğu görülmektedir (ASTM Kart No: 00-0361451).

Kristalleşme seviyesi belirlenirken XRD kırınım desenlerinde gözlenen tüm 
pikler için ayrı ayrı hesaplama yapılmış ve $34.38^{\circ}$ deki (002) doğrultusunda tercihli bir yönelime sahip olduğu belirlenmiştir. (002) doğrultusundaki pikin yarı pik genişliğinin dar olması ve pik şiddetinin yüksek olması da kristalleşme seviyesinin iyi olduğunu gösterir.

Ayrıca, ZnO filminin hekzgonal wurtzite kristal yapısına sahip olduğu ve (002) doğrultusundaki büyüme için tane büyüklüğü $280 \mathrm{~nm}$ olarak tespit edilmiştir. Buna göre, SILAR tekniği ile ZnO filmlerinin iyi kristalleşme seviyesine sahip olacak şekilde üretildiği görülmüştür.

Şekil 2 (b) incelendiğinde; $\mathrm{CuO}$ filmlerine ait kırınım deseninde; (110), $(-111),(-202), \quad(020), \quad(202), \quad(-113)$, (-311), (220), (311) ve (-222) olmak üzere on bir adet pik olduğu saptanmiştır (ASTM KART NO: 050661). Tablo 1'de yapılanma katsayıları da incelendiğinde, $\mathrm{CuO}$ filmlerinde tek bir doğrultuda tercihli bir büyümenin olmadığı ve farklı doğrultularda (110), (-111), (111), (-202), (020) baskın büyümelerin olduğu görülmektedir. Benzer sonuçlar literatürdeki diğer çalışmalarda da görülmüştür [34,35].

Bakır oksit filmlerinin $\mathrm{CuO}$ tenorite fazında kristalleştiği tespit edilmiştir ve başka herhangi bir bakır oksit fazına rastlanılmamıştır. Tablo 1'deki makro gerilme ve dislokasyon yoğunlukları incelendiğinde, her iki filmde de değerlerin 10-12-10-15 (çizgi $/ \mathrm{m}^{2}$ ) mertebesinde olduğu görülmektedir. Makro gerilme değerlerinin negatif olması filmlerin kristal yapısında sıkışma, pozitif olması ise gevşeme olduğunu göstermektedir. Literatürde de benzer sonuçlar görülmüştür [36]. Ayrıca $\mathrm{CuO}$ filmi içn belirlenen doğrultularda hesaplanan tane büyüklüklerinin 218-185 nm arasında değiştiği görülmüştür.
$\mathrm{CuO}$ filmlerinin kristalleşmesinde baskın yönelim olduğundan her bir yönelim için farklı tane büyüklüğü değerleri hesaplanmıştır. Bu verilerden yararlanarak ortalama tane büyüklüğü 202 nm olarak belirlenmiştir. XRD sonuçlarına göre, Rajkumar P.V. [37], Rahman M. A. [38], Shishodia P. K. [39], Chand P. [40], Wang F. [41] ve arkadaşlarının yapmış olduğu çalışmalardaki sonuçlarla kıyaslandığında, $\mathrm{ZnO}$ ve $\mathrm{CuO}$ filmlerinin kristalleşme seviyeleri daha iyi olduğu görülmüştür.

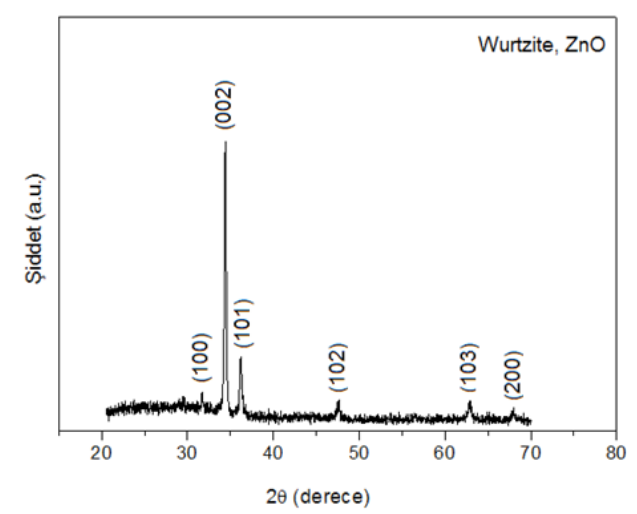

(a)

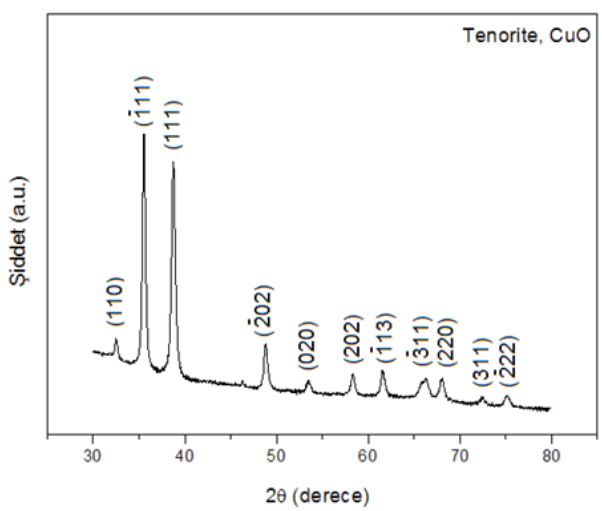

(b)

Șekil 2. (a) $\mathrm{ZnO}$ ve (b) $\mathrm{CuO}$ filmlerinin XRD kırınım desenleri 
O. Gençyılmaz vd. / Fotovoltaik Güneş Pillerinde kullanılan ZnO ve CuO Filmlerinin SILAR Yöntemi ile Üretilmesi ve Karakterizasyonu

Tablo 1. $\mathrm{ZnO}$ ve $\mathrm{CuO}$ filmlerinin XRD desenlerinden elde edilen veriler

\begin{tabular}{|c|c|c|c|c|c|c|c|c|}
\hline Film & $2 \theta\left(^{\circ}\right)$ & $d(\AA)$ & (hkl) & $\begin{array}{l}\text { Kristal } \\
\text { Sistemi }\end{array}$ & $\begin{array}{c}\text { TC } \\
\text { (hkl) }\end{array}$ & $\begin{array}{c}\delta \\
(\text { çizgi/m²) }\end{array}$ & $\begin{array}{c}\mathrm{D} \\
(\mathrm{nm})\end{array}$ & $<\mathrm{e}>$ \\
\hline \multirow{5}{*}{$\mathrm{ZnO}$} & 31.99 & 2.811 & $(100)$ & \multirow{5}{*}{ 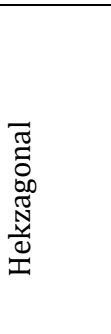 } & 0.30 & $1.20 \times 10^{-14}$ & 287 & $-8.88 \times 10^{-4}$ \\
\hline & 34.38 & 2.544 & $(002)$ & & 3.46 & $3.57 \times 10^{-12}$ & 280 & $2.27 \times 10^{-2}$ \\
\hline & 36.20 & 2.479 & (101) & & 0.39 & $1.58 \times 10^{-14}$ & 250 & $1.41 \times 10^{-3}$ \\
\hline & 47.48 & 1.913 & $(102)$ & & 0.70 & $8.01 \times 10^{-15}$ & 353 & $1.15 \times 10^{-3}$ \\
\hline & 62.85 & 1.477 & (103) & & 0.94 & $9.89 \times 10^{-14}$ & 317 & $6.77 \times 10^{-5}$ \\
\hline \multirow{6}{*}{$\mathrm{CuO}$} & 32.50 & 2.752 & $(110)$ & \multirow{6}{*}{ 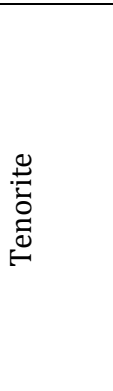 } & 1.06 & $4.58 \times 10^{-12}$ & 218 & $3.63 \times 10^{-4}$ \\
\hline & 35.55 & 2.522 & $\overline{(111)}$ & & 1.51 & $4.60 \times 10^{-12}$ & 217 & $-1.98 \times 10^{-4}$ \\
\hline & 38.74 & 2.322 & (111) & & 1.42 & $5.40 \times 10^{-12}$ & 185 & $-4.30 \times 10^{-4}$ \\
\hline & 48.83 & 1.863 & $\overline{(202)}$ & & 1.14 & $5.23 \times 10^{-12}$ & 191 & $1.44 \times 10^{-3}$ \\
\hline & 53.55 & 1.709 & $(020)$ & & 1.02 & $5.10 \times 10^{-12}$ & 196 & $-2.50 \times 10^{-3}$ \\
\hline & 58.36 & 1.579 & (202) & & 0.95 & $4.83 \times 10^{-12}$ & 207 & $-6.95 \times 10^{-4}$ \\
\hline
\end{tabular}

\subsection{Optik Analizler}

$\mathrm{Bu}$ çalışmada, $\mathrm{ZnO}$ ve $\mathrm{CuO}$ filmlerinin kalınlıklarını belirlemek için spektroskopik elipsometri (SE) tekniği kullanılmıştır. Teorik model olarak Cauchy-Urbach modeli seçilmiştir. ZnO ve $\mathrm{CuO}$ filmlerinin soğurma ve geçirgenlik spektrumları göz önüne alınarak her bir film için uygun ve standart dalgaboyu aralığı 300-900 nm olarak belirlenmiştir. Ayrıca bu teknik ile kalınlığın belirlenmesi için film yüzeyine gelen ışığın gelme açısı da önemli bir parametredir. Film yüzeyine gelen işığın şiddeti yansıyan ve analizöre ulaşan ışığın şiddetini ve fazını etkilediği için, $\mathrm{ZnO}$ ve $\mathrm{CuO}$ filmlerinin yüzeyine farklı gelme açllarında $\left(50^{\circ}\right.$, $60^{\circ}$ ve $70^{\circ}$ ) polarize ışık gönderilerek $\cos (\Delta)$ ve psi $(\psi)$ spektrumları alınmıştır. Elde edilen spektrumlar incelenerek, $\mathrm{ZnO}$ ve $\mathrm{CuO}$ filmleri için en uygun gelme açısı sırasıyla $70^{\circ}$ ve $60^{\circ}$ olarak belirlenmiştir. Belirlenen ölçüm parametreleri ile $\mathrm{ZnO}$ için $\cos (\Delta)$ ve $\mathrm{CuO}$ için psi $(\psi)$ değerleri ölçülmüştür. Deneysel olarak elde edilen $\cos (\Delta)$ ve psi $(\psi)$ değerleri ile Cauchy-Urbach modeli kullanılarak teorik olarak belirlenen $\cos (\Delta)$ ve psi $(\psi)$ değerleri arasındaki uyumu sağlamak için yaklaştırma işlemi yapılmıştır. Teorik model ve deneysel veriler arasındaki uyumun en iyi olduğu spektrumlardan yararlanılarak $\mathrm{ZnO}$ ve $\mathrm{CuO}$ filmlerin kalınlıkları belirlenmiştir. 
O. Gençyılmaz vd. / Fotovoltaik Güneş Pillerinde kullanılan ZnO ve CuO Filmlerinin SILAR Yöntemi ile Üretilmesi ve Karakterizasyonu

$\mathrm{Bu}$ yaklaştırma işleminde teorik ve deneysel veriler arasındaki uyumun iyi olması $\cos (\Delta)$-psi $(\psi)$ spektrumlarına ait MSE (Mean Square Error) değerlerinin küçük olması ile ilișkilidir. Şekil 3'te $\mathrm{ZnO}$ ve $\mathrm{CuO}$ filmlerine ait deneysel ve teorik $\cos (\Delta)$ ve psi $(\psi)$ spektrumları verilmektedir. Şekil 3'te görüldüğü gibi, deneysel ve teorik veriler arasında çok az sapma vardır bu durumu Tablo 2'deki küçük MSE değerleri desteklemektedir. $\mathrm{Bu}$ sapmaların oluşmasındaki en temel etken $\mathrm{ZnO}$ ve $\mathrm{CuO}$ filmlerinin yüzey özellikleridir. Daha önce de bahsedildiği gibi, SE tekniğinde alınan ölçümler gelen ışı̆̆ın filmin yüzeyinden yansıması sonucu elde edilmektedir. Filmlerin yüzeyindeki pürüzlülük, yüzeyin homojenliğinin farklı olması, yüzeyden ve tane sinırlarından yansıma olayları ölçümleri etkileyen en önemli faktörlerdir. Ayrica taban olarak kullanılan camlardan gelen yansımaların da deneysel sonuçları etkileyebileceğini söyleyebiliriz. Her bir film için SE ölçümleri sonucunda belirlenen kalınlık değerleri $(t)$ ile Cauch-Urbach model parametreleri Tablo 2'de verilmektedir. Şekil 4'te filmlerin kırılma indisi $(n)$ ve sönüm katsayısının $(k)$ dalgaboyuna bağlı olarak değişimi görülmektedir. Görünür bölgede $\mathrm{CuO}$ filmlerinin kırlma indisi değerlerinin daha yüksek olduğu ve uzun dalgaboylarında ise her iki filmin de kırılma indisi değerlerinin hemen hemen sabit kaldığı görülmüştür.

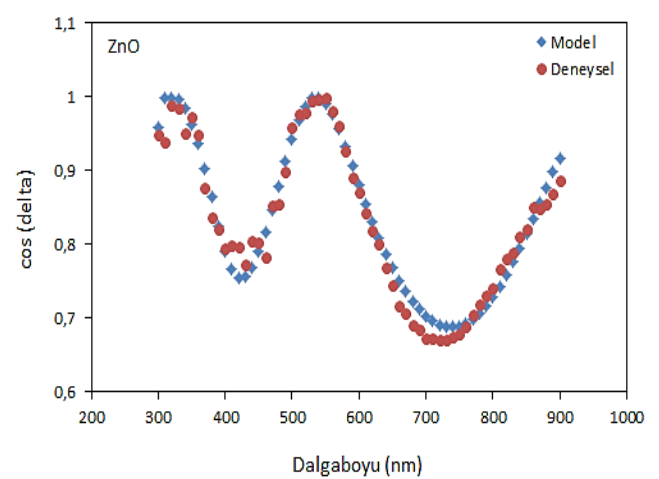

(a)

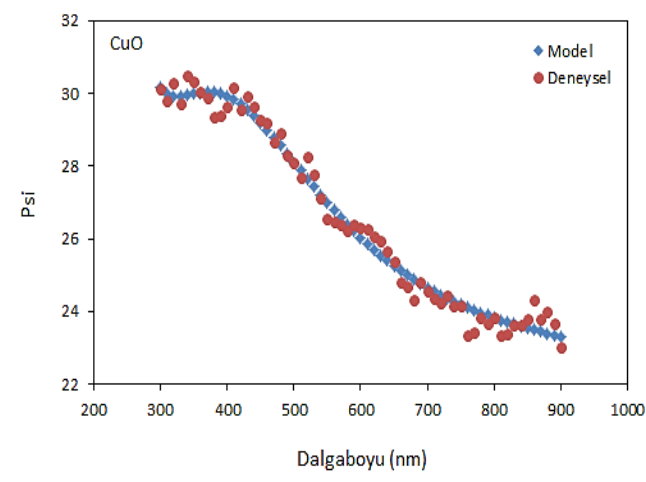

(b)

Şekil 3. $\mathrm{ZnO}$ ve $\mathrm{CuO}$ filmlerinin $\cos (\Delta)$ ve psi $(\psi)$ spektrumları

Tablo 2. $\mathrm{ZnO}$ ve $\mathrm{CuO}$ filmlerinin kalınlıkları $(t)$ ve modelleme parametreleri

\begin{tabular}{|l|c|c|}
\hline \multirow{2}{*}{ Optik Parametreler } & \multicolumn{2}{|c|}{ Film } \\
\cline { 2 - 3 } & ZnO & CuO \\
\hline $\mathrm{t}(\mathrm{nm})$ & 94 & 143 \\
\hline $\mathrm{A}_{\mathrm{n}}$ & 2.42 & 2.23 \\
\hline $\mathrm{B}_{\mathrm{n}} \times 10^{-2}(\mathrm{~nm})^{2}$ & 5.31 & 5.35 \\
\hline $\mathrm{C}_{\mathrm{n}} \times 10^{-2}(\mathrm{~nm})^{4}$ & 1.86 & 1.93 \\
\hline $\mathrm{A}_{\mathrm{k}}$ & 1.16 & 0.234 \\
\hline $\mathrm{B}_{\mathrm{k}}(\mathrm{eV})^{-1}$ & 3.46 & 5.41 \\
\hline $\mathrm{MSE}$ & 0.28 & 0.32 \\
\hline
\end{tabular}


O. Gençyılmaz vd. / Fotovoltaik Güneş Pillerinde kullanılan ZnO ve CuO Filmlerinin SILAR Yöntemi ile Üretilmesi ve Karakterizasyonu

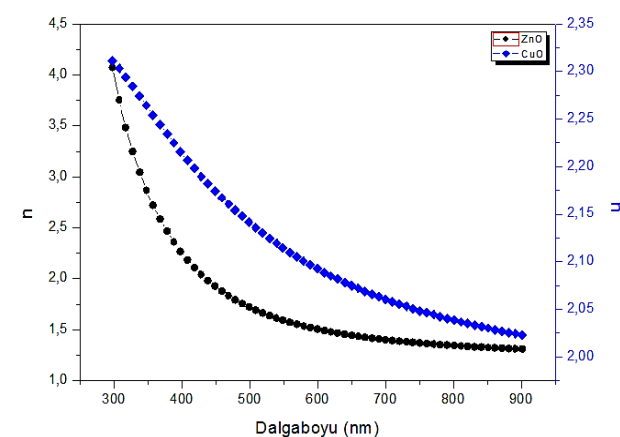

(a)

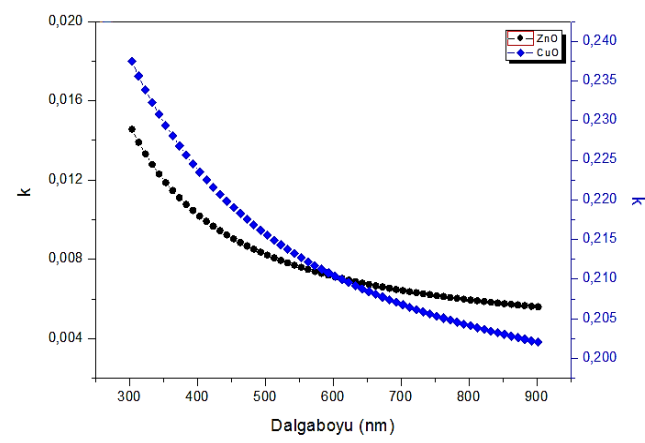

Sekil 4. $\mathrm{ZnO}$ ve $\mathrm{CuO}$ filmlerinin (a) kırılma indisi $(n)$ ve (b) sönüm katsayısı $(k)$ spektrumları

$\mathrm{ZnO}$ ve $\mathrm{CuO}$ filmlerinin $300-900 \mathrm{~nm}$ dalgaboyu aralığında UV spektrofotometresi kullanılarak elde edilen geçirgenlik spektrumları Şekil 5 'te verilmektedir. Spektrumlar incelendiğinde, filmlerin uzun dalgaboylarında saydam malzemeler olarak davranış sergilediği görülmektedir. Filmlerin geçirgenlik değerleri; ZnO filmleri için $\sim 600 \mathrm{~nm}$ ve $\mathrm{CuO}$ filmleri için ise $\sim 800 \mathrm{~nm}$ 'den daha kısa dalgaboylarında belirgin bir şekilde azaldığı görülmektedir. Geçirgenlik değerlerinde bu azalışın gözlendiği bu bölgeler, filmlerin temel soğurma bölgeleridir.

Ayrıca, ZnO filminin geçirgenlik değerlerinin görünür bölgede (400-700 $\mathrm{nm}) \sim \%$ 60, $\mathrm{CuO}$ filminin ise aynı bölgede de $\sim \quad \% \quad 5$ gibi düşük bir geçirgenliğe sahip oldukları belirlenmiștir. $\mathrm{Bu}$ geçirgenlik değerleri fotovoltaik güneş pili kullanımında $\mathrm{ZnO}$ filmleri için daha yüksek değerlerde olabilir. ZnO filmleri için geçirgenliğin düșük olmasının nedeni yüzey özellikleridir. Yüzey görüntülerinde de görüleceği gibi (Şekil 9); filmin yüzeyinde büyük taneli ve yığılma şeklindeki oluşumların varlığı kendini göstermiștir. Bu yüzey özellikleri, filmin yüzeyinde yansıma veya saçılma yolu ile kayıplara neden olmasından dolayı filmin geçirgenlik değerinin az olmasına neden olabilir. Yüksek soğurma özelliğinden dolayı fotovoltaik güneş pillerinde soğurucu tabaka olarak kullanılan $\mathrm{CuO}$ filmleri için ise bu geçirgenlik değeri uygundur.
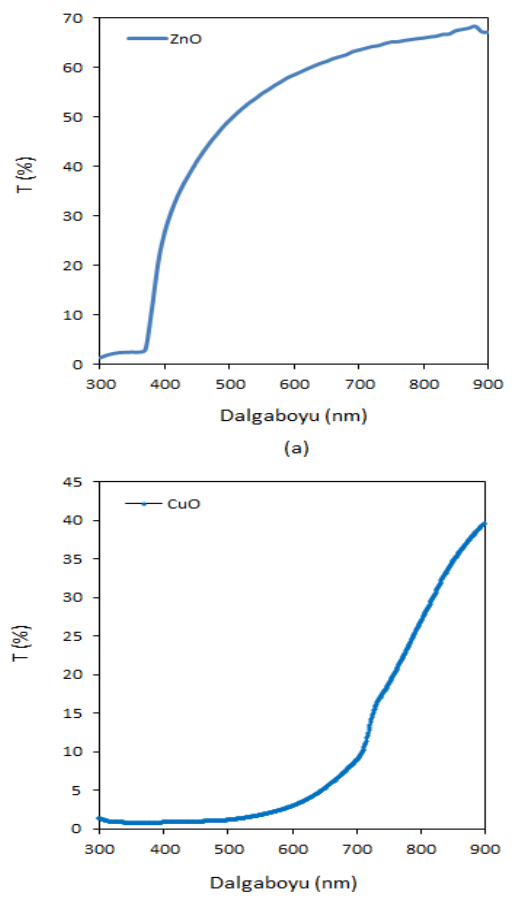

(b)

Şekil 5. (a) $\mathrm{ZnO}$ ve (b) $\mathrm{CuO}$ filmlerinin geçirgenlik spektrumları 
O. Gençyılmaz vd. / Fotovoltaik Güneş Pillerinde kullanılan ZnO ve CuO Filmlerinin SILAR Yöntemi ile Üretilmesi ve Karakterizasyonu

ZnO ve CuO filmlerinin soğurma spektrumları Şekil 6' da verilmektedir. $\mathrm{Bu}$ spektrumlar incelendiğinde, $\mathrm{ZnO}$ filmleri için uzun dalgaboylarından kısa dalgaboylarına gidildikçe soğurma değerlerinin az bir artış gösterdiği ve daha kısa dalgaboylarında ise soğurma değerlerinde belirgin bir artışın olduğu görülmektedir. CuO filmlerinde ise; kısa dalgaboylarına gidildikçe soğurmanın yavaş yavaş arttığı görülmüştür.

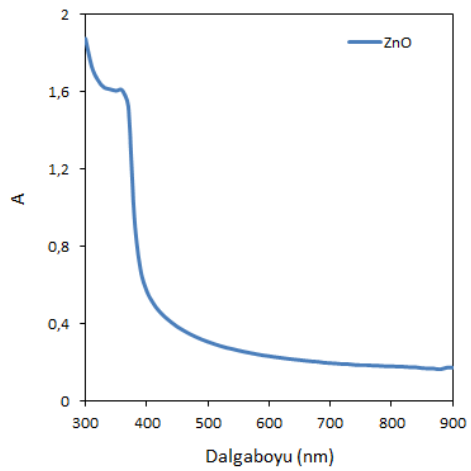

(a)

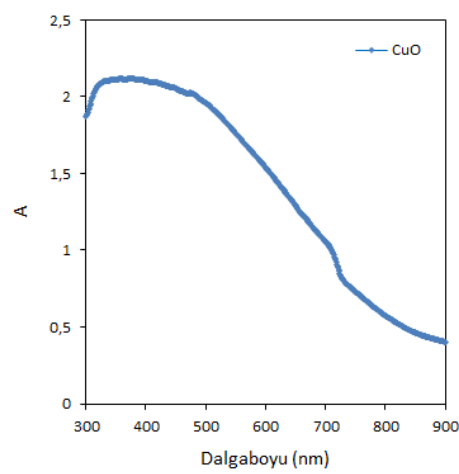

(b)

Şekil 6. (a) $\mathrm{ZnO}$ ve (b) $\mathrm{CuO}$ filmlerinin soğurma spektrumları

$\mathrm{ZnO}$ ve $\mathrm{CuO}$ filmlerinin yansıma spektrumları Şekil 7' de verilmektedir. Yansıma spektrumları incelendiğinde; ZnO filmlerinin yansıma değerlerinin görünür bölgede düşük iken $\mathrm{CuO}$ filmlerinin yansıma değerlerinin daha yüksek olduğu saptanmıştır. Ayrıca filmlerin uzun ve kısa dalgaboylarındaki davranışlarının farklı olduğu görülmektedir.

ZnO filmlerinin yansıma değerleri uzun dalgaboylarından kısa dalgaboylarına giderken azalmıştır.

$\mathrm{CuO}$ filmlerin ise uzun dalga boylarında yansıma değerleri hemen hemen sabit iken 300-400 nm dalgaboyu aralığında belirgin bir azalma olduğu görülmüştür. Ayrica $\mathrm{CuO}$ filmlerinin yansima değerleri ZnO filmlerinin yansıma değerlerine göre daha yüksektir. Bunun sebebi; filmlerin yüzey özelliklerinden kaynaklanabilir. Tane sinırları, yüzey pürüzlülüğü ve morfoloji bir malzemeden yansıyan ışığın şiddetini etkileyen faktörlerdir. $\mathrm{Bu}$ sebeple yüksek yansıma değerlerine sahip olan $\mathrm{CuO}$ filmlerinin $\mathrm{ZnO}$ filmlerine göre daha homojen bir yüzeye sahip olabileceğini söyleyebiliriz.
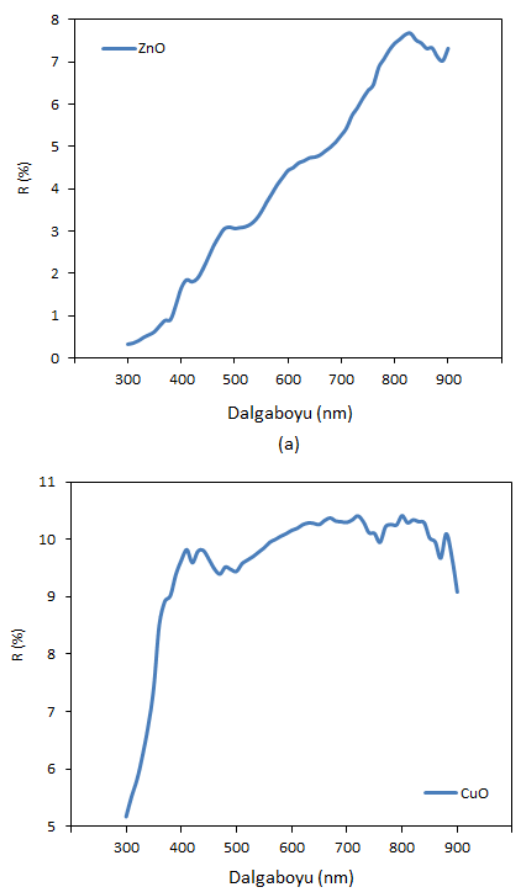

(b)

Şekil 7. (a) $\mathrm{ZnO}$ ve (b) $\mathrm{CuO}$ filmlerinin yansıma spektrumları 
O. Gençyılmaz vd. / Fotovoltaik Güneş Pillerinde kullanılan ZnO ve CuO Filmlerinin SILAR Yöntemi ile Üretilmesi ve Karakterizasyonu

$\mathrm{ZnO}$ ve $\mathrm{CuO}$ filmleri için $(\alpha h v)^{2} \sim h v$ değişim grafikleri çizilerek, optik metot ile bant aralığı değerleri hesaplanmıștır. $(\alpha h v)^{2} \sim h v$ değişim grafikleri Şekil 8'de gösterilmiştir. $\mathrm{Bu}$ grafiklerin lineer kısımlarının doğrultularının $h v$ eksenini $(\alpha h v)^{2}=0^{\prime}$ da kestiği noktaların enerji değerlerinden yasak enerji aralıkları belirlenmiștir.

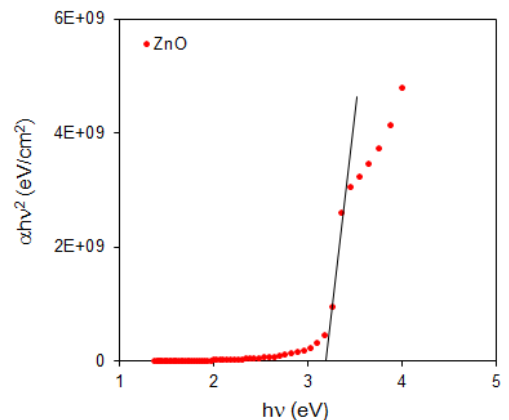

(a)

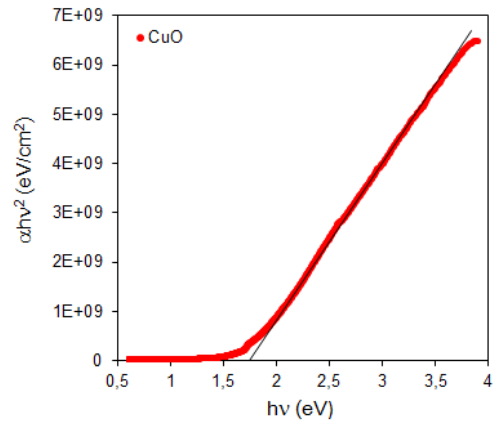

(b)

Şekil 8. (a) $\mathrm{ZnO}$ ve (b) $\mathrm{CuO}$ filmlerinin $(\alpha h v)^{2} \sim h v$ değişim grafikleri

$\mathrm{ZnO}$ ve $\mathrm{CuO}$ filmlerinin direkt geçişe sahip oldukları ve yasak enerji aralığı değerlerinin sırasıyla $3.22 \mathrm{eV}$ ve $1.72 \mathrm{eV}$ olduğu belirlenmiștir ve bu değerler literatür ile uyumludur [37]. ZnO ve $\mathrm{CuO}$ filmleri için hesaplanan yasak enerji aralığı değerleri fotovoltaik güneş pili uygulamaları için uygundur.

\subsection{Yüzeysel ve Elektrikse Analizler}

$\mathrm{ZnO}$ ve $\mathrm{CuO}$ filmlerinin AKM kullanılarak elde edilen yüzey görüntüleri Şekil 9'da verilmektedir. ZnO'in AKM görüntüsünden, yüzeyde birbirinden ayırt edilebilir taneli bir yapilanmanın tam olarak gerçekleşmediği, yüzeyde rastgele dağılmış farklı genişlik ve yüksekliklere sahip tepe tipi oluşumların dikkat çektiği, tane boşluklarının (siyah bölgeler) bulunduğu ve tanelerin üst üste binmesi sonucu oluşan yüksek kümelerin (beyaz bölgeler) oluştuğu belirlenmiștir. $\mathrm{Bu}$ beyaz bölgelerin yığılma şeklindeki yüksek büyüme mekanizmasından (kümelenme) veya deney esnasında çöktürülen kirliliklerden kaynaklandığını düșünmekteyiz. ZnO filminin olușum mekanizmasının karışık büyüme (mixed growth) şeklinde gerçekleştiği söylenebilir.

CuO filmlerinin görüntüleri incelendiğinde ise, filmin oluşumunda yüzeye dağılımlarının nispeten homojen olduğu belirlenmiștir. Ayrıca yüzeyde oluşan tane boşluklarının dağılımı ZnO filmlerinkine göre değişim göstermiștir. CuO filminde yüzey morfolojisi taneli yapıdan farklı olarak kanal şeklindeki oluşumlarla dikkati çekmektedir. Ayrıca bu kanal tipi oluşumlarda filmin yüzeyinde renk tonu farkı olușturarak kendini göstermektedir.

$\mathrm{Bu}$ görüntülerde $\mathrm{CuO}$ filmleri daha homojen bir yüzey morfolojisine sahip olduğunu söyleyebiliriz. $\mathrm{ZnO}$ ve $\mathrm{CuO}$ filmlerin $R_{q}$ (rms pürüzlülük), $R_{a}$ (ortalama pürüzlülük) ve $R_{p v}$ (pik-vadi pürüzlülük) pürüzlülük Tablo $3^{\prime}$ te verilmektedir. Tablo 3 incelendiğinde, ZnO filminin yüzey pürüzlülük değerinin $\mathrm{CuO}$ filminkine göre daha düşük olduğu dikkat çekmektedir. $\mathrm{Bu}$ durumun filmlerin oluşum sırasında, film yüzeylerinde tane boşluklarının 
O. Gençyılmaz vd. / Fotovoltaik Güneş Pillerinde kullanılan ZnO ve CuO Filmlerinin SILAR Yöntemi ile Üretilmesi ve Karakterizasyonu

daha az olması, tanelerin yüzeye yükselti olarak dağılması ve sıkı paketlenmiş tanelerin oluşması pürüzlülük değerlerinin değișmesine sebep olabilir.
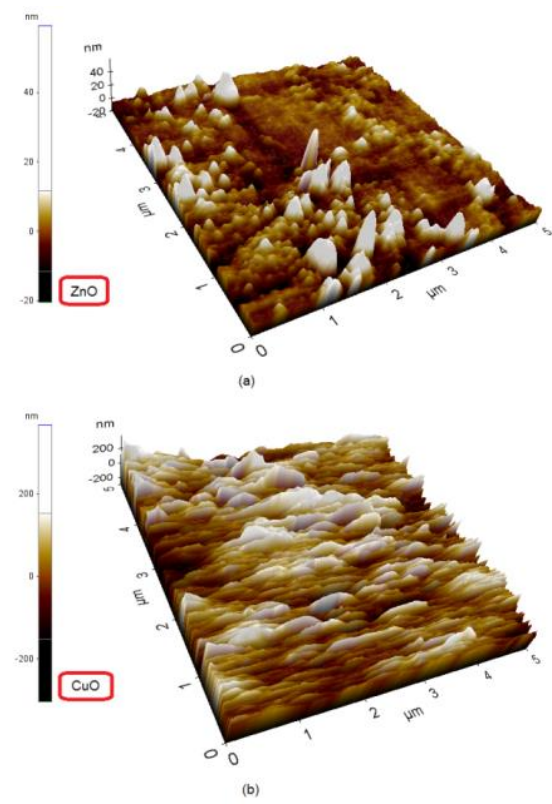

Şekil 9. (a) ZnO ve (b) CuO filmlerinin AKM görüntüleri

Üretilen $\mathrm{ZnO}$ ve $\mathrm{CuO}$ filmlerinin elektriksel özdirenç değerlerinin ve iletim tipinin belirlenmesi için dört-uç ve sıcak-uç metodu kullanılmıştır. ZnO ve $\mathrm{CuO}$ filmlerin elektriksel özdirenç değerleri sırasiyla $8.37 \times 10^{-4} \Omega \mathrm{cm}$ ve $1.36 \times 10^{-2} \Omega \mathrm{cm}$ olarak belirlenmiștir. Ayrıca filmlere sıcak uç tekniği uygulayarak $\mathrm{ZnO}$ filmlerinin n-tipi ve $\mathrm{CuO}$ filmlerinin ise p-tipi iletim özelliği gösterdiği tespit edilmiştir. Belirlenen elektriksel özdirenç değerleri ve iletim tipleri fotovoltaik güneş pili kullanımı için uygundur.
Tablo 3. ZnO ve $\mathrm{CuO}$ filmlerinin pürüzlülük değerleri

\begin{tabular}{|c|c|c|c|}
\hline Film & $\begin{array}{c}R_{a} \\
(\mathrm{~nm})\end{array}$ & $\begin{array}{c}R_{q} \\
(\mathrm{~nm})\end{array}$ & $\begin{array}{c}R_{p v} \\
(\mathrm{~nm})\end{array}$ \\
\hline $\mathrm{ZnO}$ & 38 & 59 & 79 \\
\hline $\mathrm{CuO}$ & 60 & 77 & 670 \\
\hline
\end{tabular}

\section{Tartışma ve Sonuç}

$\mathrm{Bu}$ çalışmada; $\mathrm{ZnO}$ ve $\mathrm{CuO}$ filmleri, basit ve ekonomik bir teknik olması ile dikkat çeken SILAR tekniği kullanılarak üretilmiştir. Fotovoltaik güneş pillerinde ve çeşitli opto-eletronik aygıtlarda uygulama potansiyeli yüksek olan bu filmlerin yapısal, optiksel, elipsometrik, yüzeysel ve elektriksel özellikleri uygun analiz teknikleri kullanılarak analiz edilmiş ve belirtilen özellikler incelenmiștir.

$\mathrm{ZnO}$ ve $\mathrm{CuO}$ filmlerinin yapisal özelliklerini XRD desenleri kullanılarak incelenmiștir. XRD desenlerinin incelenmesi sonucunda, her iki filminde polikristal yapıda oluştukları belirlenmiștir.

$\mathrm{ZnO}$ ve $\mathrm{CuO}$ filmlerinin sirası ile hekzagonal wurtzite ve tenorite kristal sistemine sahip oldukları görülmüștür. Ayrica her iki filmde de kristalleşme seviyesinin iyi olduğu saptanmıştır. Yapılanma katsayı (TC) değerleri hesaplanarak; ZnO filmlerinin (002) tercihli yönelime sahip olduğu, $\mathrm{CuO}$ filmlerinin ise farklı doğrultularda baskın yönelime sahip olarak kristalleştiği belirlenmiștir.

Ayrica, $\mathrm{ZnO}$ ve $\mathrm{CuO}$ filmlerinin geçirgenlik, soğurma ve yansıma spektrumları incelenmiştir. Geçirgenlik değerlerinin literatüre göre daha düşük olduğu görülmüștür. Optik metot 
O. Gençyılmaz vd. / Fotovoltaik Güneş Pillerinde kullanılan ZnO ve CuO Filmlerinin SILAR Yöntemi ile Üretilmesi ve Karakterizasyonu

kullanılarak filmlerin bant aralıkları 3,22 eV (ZnO için) ve 1,72 eV (CuO için) olarak hesaplanmıștır. $\mathrm{ZnO}$ ve $\mathrm{CuO}$ filmlerin kalınlıkları spektroskopik elipsometri tekniği ve Cauchy-Urbach dispersiyon modeli kullanılarak sırası ile 94 ve $143 \mathrm{~nm}$ olarak belirlenmiştir.

Tüm filmlerin AKM görüntülerinin incelenmesi sonucunda, filmlerin tam olarak homojen bir yüzeye sahip olmadıkları ve diğer üretim teknikleri ile üretilen filmlere göre yüzey pürüzlülüklerinin yüksek olduğu belirlenmiştir.

Ayrica, $\mathrm{ZnO}$ ve $\mathrm{CuO}$ filmlerinin elektriksel özdirenç değerleri $8.37 \times 10^{-4}$ $\Omega \mathrm{cm}$ ve $1.36 \times 10^{-2} \Omega \mathrm{cm}$ ölçülmüștür. Filmlerin iletim mekanizmaları $\mathrm{ZnO}$ filmleri için n-tipi, $\mathrm{CuO}$ filmleri için ise p-tipi olarak belirlenmiştir.

Sonuç olarak $\mathrm{ZnO}$ ve $\mathrm{CuO}$ yariletken filmlerinin SILAR tekniği kullanılarak da üretilebileceği ve farklı çalışmalar yapılarak deneysel parametrelerin optimizasyonu ile film kalitesinin daha da arttırılabileceği sonucuna varılmıştır.

NOT: $\mathrm{Bu}$ çalışma, Çankırı Karatekin Üniversitesi Proje Yönetim Birimi tarafından desteklenmiştir (Proje No: FF12035B17).

\section{Kaynakça}

[1] Terasako T., Murakami T., Hyodou A., Shirakata S. 2015. Structural and electrical properties of $\mathrm{CuO}$ films and $\mathrm{n}-\mathrm{ZnO} / \mathrm{p}-\mathrm{CuO} \quad$ heterojunctions prepared by chemical bath deposition based technique, Solar Energy Materials \& Solar Cells, Cilt. 132, s. 74-79. DOI: 10.1016/j.solmat.2014.08.023

[2] Fahrenbruch A.L. 1997. II-VI Compounds in solar energy conversion, Journal of Crystal Growth, Cilt. 39, s. 73-91.
DOI:10.1016/0022-0248(77)901567

[3] Singh I., Kaur G., Bedi R.K. 2011. CTAB assited growth and characterization of nanocrystalline $\mathrm{CuO}$ films by ultrasonic spray pyrolysis technique, Applied Surface Science, Cilt., 257, No. 22, s. 95469554.

DOI:

10.1016/j.apsusc.2011.06.061

[4] Hu X., Gao F., Xiang Y., Wu H., Zheng X., Jiang J., Li J., Yang H., Liu S. 2016. Influence of oxygen pressure on the structural and electrical properties of $\mathrm{CuO}$ thin films prepared by pulsed laser deposition, Materials Letters, Cilt. 176, s. 282-284.

DOI:10.1016/j.matlet.2016.04.055

[5] Saadaldin N., Alsloum M.N., Hussain N. 2015. Preparing of Copper oxides Thin Films by Chemical Bath Deposition (CBD) for Using in Environmental Application, Energy Procedia, Cilt. 74, s. 1459-146. DOI: 10.1016/j.egypro.2015.07.794

[6] Mbulanga C. M., Urgessa Z. N., Tankio Djiokap S.R., Botha J.R., Duvenhage M. M., Swart H. C. 2016. Surface characterization of $\mathrm{ZnO}$ nanorods grown by chemical bath deposition, Physica B: Condensed Matter, Cilt. 480, S. 42-47. DOI: 10.1016/j.physb.2015.07.016

[7]Bedia A., Bedia F.Z., Aillerie M., Maloufi N., Benyoucef B. 2015. Morphological and optical properties of $\mathrm{ZnO}$ thin films prepared by spray pyrolysis on glass substrates at various temperatures for integration in solar cell, Energy Procedia, Cilt. 74 s. $\quad$ 529-538. DOI: 0.1016/j.egypro.2015.07.740

[8] Cachoncinlle C., Hebert C., Perrière J., Nistor M., Petit A., Millon E. 2015. Random lasing of $\mathrm{ZnO}$ thin films grown by pulsed-lase deposition, 
O. Gençyılmaz vd. / Fotovoltaik Güneş Pillerinde kullanılan ZnO ve CuO Filmlerinin SILAR Yöntemi ile Üretilmesi ve Karakterizasyonu

Applied Surface Science, Cilt. 336, s. 103-107. DOI: 10.1016/j.apsusc.2014.09.186

[9] Jayaraman V. K., Kuwabara Y. M., Álvarez A. M., Amador María de la luz 0. 2016. Importance of substrate rotation speed on the growth of homogeneous $\mathrm{ZnO}$ thin films by reactive sputtering, Materials Letters, Cilt. 169, s. 1-4. DOI: 10.1016/j.matlet.2016.01.088

[10] Maleki-Ghaleh H., Shahzadeh M., Hoseinizadeh S. A., Arabi A., Aghaie E., Siadati M. H. 2016. Evaluation of the photo-electro-catalytic behavior of nano-structured $\mathrm{ZnO}$ films fabricated br electrodepositon process, Materials Letters, Cilt. 169, s. 140-143. DOI: 10.1016/j.matlet.2016.01.090

[11] Armelao L., Barreca D., Bertapelle M., Bottaro G., Sada C., Tondello E. 2003. A sol-gel approach to nanophasic copper oxide thin films, Thin Solid Films, Cilt. 442, No. 1-2, S. 48-52. DOI: 10.1016/S00406090(03)00940-4

[12] Gould R.D., Rahman M.S. 1981. Power-law currents in some ZnOSn composite materials, Applied Physics, Cilt. 14, s. 79-89. DOI: 10.1088/0022-3727/14/1/011

[[13] Chen A., Long H., Li X., Li Y., Yang G., Lu P. 2009. Controlled growth and characteristics of single-phase $\mathrm{Cu} 2 \mathrm{O}$ and $\mathrm{CuO}$ films by pulsed laser deposition, Vacuum, Cilt. 83, s. 927-930. DOI: 10.1016/j.vacuum.2008.10.003

[14] Kumar A. K., Murugesan S., Suresh S., Raj S. P. 2013. Nanostructured $\mathrm{CuO}$ thin films prepared through sputtering for solar selective absorbers, Journal of Solar Energy, Article ID 147270, s.1-6. DOI: $10.1155 / 2013 / 147270$
[15] Maruyama T. 1998. Copper Oxide Thin Films Prepared from Copper Dipivaloylmethanate and Oxygen by Chemical Vapor Deposition, Japanese Journal of Applied Physics Cilt. 37 (7), s. 4099-4102. DOI: $10.1143 / J J A P .37 .4099$

[16] Ray S. C. 2001. Preparation of copper oxide thin film by the solgel-like dip technique and study of their structural and optical properties, Solar Energy Materials \& Solar Cells, Cilt. 68, s. 307-312. DOI: $10.1016 / \mathrm{S} 0927-$ 0248(00)00364-0

[17]Al-Kuhaili $\quad$ M. $\quad$ F. 2008. Characterization of copper oxide thin films deposited by the thermal evaporation of cuprous oxide $\left(\mathrm{Cu}_{2} \mathrm{O}\right)$, Vacuum, Cilt. 82 , s. 623$629 . \quad$ DOI: DOI: 10.1016/j.vacuum.2007.10.004

[18] Muiva C. M., Maabong K., Moditswe C. 2016. $\mathrm{CuO}$ nanostructured thin films synthesised by chemical bath deposition on seed layers deposited by successive ionic layer adsorption and reaction and chemical spray pyrolysis techniques, Thin Solid Films, Cilt. 616, s. 48-54. DOI: 10.1016/j.tsf.2016.07.061

[19] Thankalekshmi R. R., Rastogi A. C. 2014. Synthesis and properties of $\mathrm{Zn}(\mathrm{Cu}-\mathrm{Mn}) \mathrm{O}$ dilute magnetic semiconductor thin films by chemical spray pyrolysis technique, Journal of Analytical and Applied Pyrolysis, Cilt 107, s. 183 190. DOI: DOI: 10.1016/j.jaap.2014.02.020

[20] Singh I., Kaur G., Bed R. K. 2011. CTAB assisted growth and characterization of nanocrystalline $\mathrm{CuO}$ films by ultrasonic spray pyrolysis technique, Applied 
O. Gençyılmaz vd. / Fotovoltaik Güneş Pillerinde kullanılan ZnO ve CuO Filmlerinin SILAR Yöntemi ile Üretilmesi ve Karakterizasyonu

Surface Science, Cilt. 257 (22), s. 9546-9554. DOI: 10.1016/j.apsusc.2011.06.061

[21] Morales J., Sanchez L., Martin F., Romos-Barrado J.R., Sanchez M. 2004. Nanostructured CuO Thin Film Electrodes Prepared By Spray Pyrolysis: A Simple Method For Enhancing The Electrochemical Performance of $\mathrm{CuO}$ in Lithium Cells, Electrochimica Acta, Cilt. 49, s. 4589.

DOI:10.1016/j.electacta.2004.05.0 12

[22] Derin H., Kantarli K., 2002. Optical characterization of thin thermal oxide films on copper by ellipsometry, Applied Physics A, Cilt. $\quad 75$, s. 391-395. DOI: $10.1007 / \mathrm{s} 003390100989$

[23] Papadimitropoulos G., Vourdas N., Vamvakas V. E., Davazoglou D. 2005. Deposition and characterization of copper oxide thin films, Journal of Physics: Conference Series, Cilt. 10, s. 182$185 . \quad$ DOI: $10.1088 / 1742-$ 6596/10/1/045

[24] Sasagawa M., Nosaka Y. 2002. Electrochemical evaluation of the roles of chelating reagents in $\mathrm{Cd}$ ion adsorption on CdS surface for the successive ionic layer adsorption and reaction (SILAR) deposition, Journal of Electroanalytical Chemistry, Cilt. 536, s. 141-144. DOI: 10.1016/S0022-0728(02)01213-5

[25] Patil U. M., Gurav K. V., Joo Oh-Shim, Lokhande C. D. 2009. Synthesis of photosensitive nanograined $\mathrm{TiO} 2$ thin films by SILAR method, Journal of Alloys and Compounds, Cilt. 478, No. 1, s. 711-715. DOI:10.1016/j.jallcom.2008.11.160
[26]Gokul B., Matheswaran P., Sathyamoorthy R. 2013. Influence of annealing on ohysical properties of CdO thin films prepared by SILAR method, Journal of Materials Science \& Technology, Cilt. 29, No. 1 s. 17-21. DOI: 10.1016/j.jmst.2012.11.015

[27] Tatar D. Spray pyrolysis yöntemi ile farklı altlık sıcaklığında elde edilen Sn20 ve SnO2:F ince filmlerin bazl fiziksel özelliklerine, altlık sıcaklığının etkisinin araştırılması, Doktora Tezi, Atatürk Üniversitesi Fen Bilimleri Enstitüsü, 2015.

[28] Connoly R. 2003. Introduction to xray powder diffraction, Springer.

[29]Cullity B. D. 2001. Stock S.R. Elements of X-ray diffraction (3rd ed.), Prentice Hall.

[30]Joseph B., Gopchandran K.G., Thomas P.V., Koshy P., Vaidyan, V. K. 1999. A study on the chemical spray deposition of zinc oxide thin films and their structural and electrical properties, Materials Chemistry and Physics, Cilt. 58, s. DOI: 71-77. 10.1016/S02540584(98)00257-0

[31] Williamson G. K., Smallman R. E. 1956. III. Dislocation densities in some annealed and cold-worked metals from measurements on the X-ray debye-scherrer spectrum, Phil Mg., Cilt. 1, No.1, s. 134-34. DOI:10.1080/1478643560823807 4

[32] Zhao Z., Morel D. L., Ferekides C. S. 2002. Electrical and optical properties of thin-doped CdO films deposited by atmospheric metalorganic chemical vapour deposition, Thin Solid Films, Cilt. 413, s. 203-211. DOI: DOI: 10.1016/S0040-6090(02)00344-9 
O. Gençyılmaz vd. / Fotovoltaik Güneş Pillerinde kullanılan ZnO ve CuO Filmlerinin SILAR Yöntemi ile Üretilmesi ve Karakterizasyonu

[33] Vigil O., Vaillant L., Cruz F., Santana G., Morales-Acevedo A., ContrerasPuente G. 2000. Spray pyrolysis deposition of cadmium-zinc oxide thin films, Thin Solid Films, Cilt. 361-362, s. 53-55. DOI: 10.1016/S0040-6090(99)01061-5

[34] Bayansal F., Şahin B., Yüksel M., Çetinkara H.A. 2013. SILAR-based growth o nanostructured $\mathrm{CuO}$ thin films from alkaline baths containing saccharin as assistive, Material Letters, Cilt. 98, s. 197200. DOI:

10.1016/j.matlet.2013.02.030

[35] Akaltun Y. 2015. Effect of thickness on the structural and optical properties of $\mathrm{CuO}$ thin films grown by successive ionic layer adsorption and reaction, Thin Soldis Films, Cilt. 594, s. 30-34. DOI: 10.1016/j.tsf.2015.10.003

[36] Jayakrishnan R., Kurian A. S., Vrun G. N., Joseph M. R. 2016. Effect of vacuum annealing on the photoconductivity of $\mathrm{CuO}$ thin films grown using sequential ionic layer adsorption reaction, Material Chemistry and Physics, Cilt. 180, s. 149-155.

DOI:10.1016/j.matchemphys.2016. 05.055

[37] Rajkumar P.V., Ravichandran K. , Baneto M. , Ravidhas C., Sakthivel B., Dineshbabu N. 2015. Enhancement of optical and electrical properties of SILAR deposited ZnO thin films through fluorine doping and vacuum annealing for photovoltaic applications, Materials Science in Semiconductor Processing, Cilt. 35, s. 189-196. DOI: 10.1016/j.mssp.2015.03.010

[38] Rahman M. A., Phillips M. R., ThatTon C. 2017. Efficient multi- coloured Li-doped ZnO thin films fabricated by spray pyrolysis, Journal of Alloys and Compounds, Cilt. 691, s. 339-342. DOI: 10.1016/j.jallcom.2016.08.242

[39] Dhruvashi, Shishodia P. K. 2016. Effect of cobalt doping on $\mathrm{ZnO}$ thin films deposited by sol-gel method, Thin Solid Films, Cilt. 612, s. 55-60. DOI: $10.1016 /$ j.tsf.2016.05.028

[40] Chand P., Gaur A., Kumar Ash., Gaur U. K. 2014. Structural and optical study of Li doped $\mathrm{CuO}$ thin films on Si $\left(\begin{array}{lll}1 & 0 & 0\end{array}\right)$ substrate deposited by pulsed laser deposition, Applied Surface Science, Cilt. 307, s. 280 286.

DOI: 10.1016/j.apsusc.2014.04.027

[41] Wang F., Wang Y., Chen L., Wei B., Hao S. 2016. Effects of surface oxygen on carbon films synthesized by plasma enhanced chemical vapor deposition, Material Letters, Cilt. 182, s. 52-54. DOI: 10.1016/j.matlet.2016.06.082

[42] Baviskar K. P., Nikam P. R., Gargote S. S., Ennaoui A., Sankpal B. R. 2013. Controlled synthesis of $\mathrm{ZnO}$ nanostructures with assorted morphologies via simple solution chemistry, Journal of Alloys and Compounds, Cilt. 551, s. 233-242. DOI:10.1016/j.jallcom.2012.10.052 